\title{
PENERAPAN MODEL PROBLEM BASED LEARNING UNTUK MENINGKATKAN KEMAMPUAN MENULIS TEKS PROSEDUR OLEH SISWA KELAS XI MAN I MEDAN TAHUN PEMBELAJARAN 2019/2020
}

Sri Listiana Izard an Nur Afrida

Universitas Muhammadiyah Sumatera Utara srilistiana@umsu.ac.id

\begin{abstract}
Abstrak. Penelitian ini bertujuan untuk meningkatkan kemampuan menulis teks prosedur siswa kelas XI Mia I di MAN I Medan dengan model problem based learning tahun Pembelajaran 2019/2020.. Penelitian ini dilaksanakan din aekolah MAN I Medan. Subjek penelitianini adalah seluruh siswa kelas XI Mia I di MAN I Medan tahun Pmbelajaran 2019-2020 yang berjumlah 35 orang terdiri dari 1 kelas. Objek penelitian ini adalah meningkatkan kemampuan menulis teks prosedur siswa kelas XI Mia I di MAN I Medan dengan model problem based learning tahun Pembelajaran 2019/2020. Metode penelitian ini mengacu pada bentuk desain bercorak Penelitian Tindakan Kelas (classroom action research). Penelitian PTK dilaksanakan dengan prosedur ; tahap perencanaan,,tahap observasi,,tahap pelaksanaan, dan ,tahap refleksi. Adapun besar peningkatan aktifitas menulis teks prosedu siswa adalah sebesar $2.33 \%$ dan peningkatan nilai secara klasikal dari hasil tes hasil belajar I ke tes hasil belajar II adalah sebesar $27,33 \%$ atau terjadi peningkatan nilai rata - rata hasil belajar sebesar 5,59.
\end{abstract}

Kata Kunci : Problem Based Learning, Kemampuan Menulis Teks Prosedur

\begin{abstract}
This study aims to improve the ability to write procedure text for class XI Mia I students in MAN I Medan with a problem based learning model in 2019/2020 Learning Year. This research was conducted at MAN I Medan school. Research subject these are all students of class XI Mia I at MAN I Medan year learning 2019-2020, amounting to 35 people consisting of 1 class. The object of this study was to improve the ability to write procedure text for class XI Mia I students in MAN I Medan with a problem based learning model in 2019/2020 Learning year. This research method refers to the classroom action research design. CAR research is carried out by procedure; the planning stage, the observation stage, the implementation phase, and, the reflection phase. The magnitude of the increase in activities to write student procedural texts was $2.33 \%$ and the increase in classical scores from the results of the first learning achievement test to the second learning achievement test was $27.33 \%$ or an increase in the average value of learning outcomes by 5.59 .
\end{abstract}

Keywords: Problem Based Learning, Ability to Write Procedure Text 


\section{PENDAHULUAN}

Kurikulum 2013 adalah pembelajaran berbasis teks dengan menggunakan pendekatan saintifik. Dalam pendekatan saintifik terdapat proses pembelajaran yang tersusun secara sistematis melalui empat tahap kegiatan, yaitu membangun konteks, pemodelan teks, membangun teks secara bersama-sama, dan pembangunan teks secara mandiri. Agar tercapai tujuan pembelajaran tersebut maka guru harus kreatif agar siswa aktif dalam kelas sehingga proses pembelajaran yang tersusun secara sistematis tersebut dapat membentuk pemikiran siswa yang sistematis dan tujuan pembelajaranpun dapat tercapai dengan baik. Di dalam Kurikulum 2013 ini siswa diharapkan lebih aktif sedangkan guru berperan sebagai fasilisator.

Teks merupakan satuan bahasa yang dimediakan secara tulis atau lisan dengan tata organisasi tertentu untuk mengungkapkan makna dalam konteks tertentu. Banyak macam-macam teks dalam Kurikulum 2013, salah satunya teks prosedur. Teks prosedur merupakan teks yang berisi tujuan dan langkah-langkah yang harus diikuti agar suatu pekerjaan dapat dilakukan. Selain itu, penggunaan model pembelajaran yang kurang bervariasi juga menyebabkan pembelajaran menjadi kurang menarik. Siswa menjadi malas dan tidak termotivasi.

Untuk itu perlu model-model pembelajaran yang tepat untuk digunakan sehingga proses belajar mengajar berjalan dengan baik. Dengan model Project Based Learning (PBL) atau model pembelajaran berbasis proyek (PBP) merupakan model pembelajaran yang menggunakan proyek/ kegiatan sebagai media, guru menugaskan siswa untuk melakukan eksplorasi, penilaian, interpretasi, sintesis, dan informasi untuk menghasilkan berbagai bentuk hasil belajar. Model pembelajaran ini menggunakan masalah sebagai langkah awal dalam mengumpulkan dan mengintegrasikan pengetahuan baru berdasarkan pengalamannya dalam beraktivitas secara nyata.

Menurut B.Baron (1998); Project Based Learning (PBL) adalah pendekatan cara pembelajaran secara konstruktif untuk pendalaman pembelajaran dengan pendekatan dengan berbasis riset terhadap permasalahan dan pertanyaan yang berbobot, nyata dan relevan bagi kehidupannya. Sementara itu Boud dan Felleti mengemukakan bahwa PBL adalah pendekatan komprehensif untuk pengajaran dan pembelajaran yang dirancang agar pelajaran melakukan riset terhadap permasalahan nyata.

Berdasarkan uraian-uraian tersebut penulis berkeinginan untuk melakukan penelitian dengan judul "Penerapan Model Problem Based Learning Untuk Meningkatkan Kemampuan Menulis Teks Prosedur Oleh Siswa Kelas Xi Man I Medan Tahun Pembelajaran 2019/2020."

\section{METODE PENELITIAN}

Desain penelitian yang digunakan mengacu pada bentuk desain bercorak Penelitian Tindakan Kelas (classroom action research). Penelitian PTK dilaksanakan dengan prosedur ; tahap perencanaan,,tahap observasi,,tahap pelaksanaan, dan ,tahap refleksi. Hal ini dapat dilihat seperti yang tercantum dalam bagan berikut.

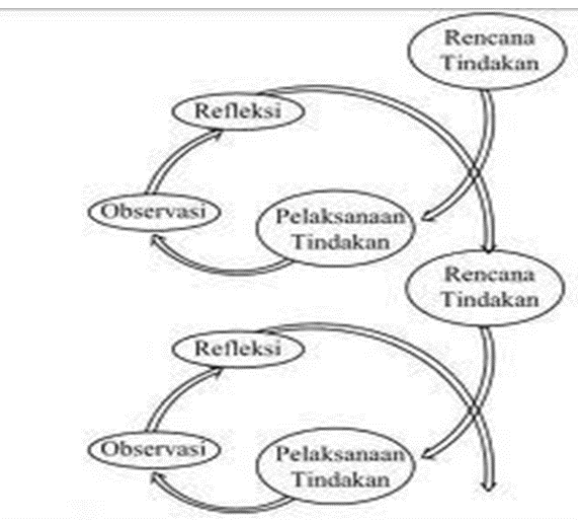

Gambar 1: Proses Alur PTK (dimodifikasi dari Burns)

Prosedur Pelaksanaan Penelitian

\begin{tabular}{|c|c|c|c|}
\hline Tahap & Kegiatan & Hasil & $\begin{array}{l}\text { Pela } \\
\text { ku }\end{array}$ \\
\hline $\begin{array}{l}\text { Identifi } \\
\text { kasi } \\
\text { masala } \\
\text { h }\end{array}$ & $\begin{array}{l}\text { Mengemuka } \\
\text { kan pendapat } \\
\text { tentang } \\
\text { membahas } \\
\text { disiplin } \\
\text { siswa } \\
\text { melalui } \\
\text { layanan } \\
\text { bimbingan } \\
\text { kelompok }\end{array}$ & $\begin{array}{l}\text { Ditemuk } \\
\text { an } \\
\text { masalah } \\
\text { yang } \\
\text { mendesa } \\
\mathrm{k} \text { untuk } \\
\text { diatasi } \\
\text { Ditemuk } \\
\text { an solusi }\end{array}$ & $\begin{array}{l}\text { Penel } \\
\text { iti }\end{array}$ \\
\hline
\end{tabular}


Sri Listiana Izard an Nur Afrida

Penerapan Model Problem Based Learning Untuk Meningkatkan Kemampuan Menulis Teks Prosedur Oleh Siswa Kelas Xi Man I Medan Tahun Pembelajaran 2019/2020

\begin{tabular}{|c|c|c|c|}
\hline & dan solusi. & & \\
\hline $\begin{array}{l}\text { Perenc } \\
\text { anaan }\end{array}$ & $\begin{array}{l}\text { Persiapan } \\
\text { Tindakan }\end{array}$ & $\begin{array}{l}\text { 1.Memb } \\
\text { erikan } \\
\text { pretes } \\
\text { menany } \\
\text { akan } \\
\text { frekuens } \\
\text { i } \\
\text { kemamp } \\
\text { uan } \\
\text { menulis } \\
\text { teks } \\
\text { prosedur } \\
\text { siswa } \\
\text { setiap } \\
\text { hari } \\
\text { 2.Mengg } \\
\text { ugah } \\
\text { perasaan } \\
\text { siswa de } \\
\text { ngan } \\
\text { mencerit } \\
\text { akan } \\
\text { riwayat } \\
\text { orang } \\
\text { sukses } \\
\text { di dunia } \\
\text { dengan } \\
\text { kegiatan } \\
\text { menulis. }\end{array}$ & $\begin{array}{l}\text { Penel } \\
\text { iti }\end{array}$ \\
\hline $\begin{array}{l}\text { Tindak } \\
\text { an } 1\end{array}$ & $\begin{array}{l}\text { Pelaksanaan } \\
\text { layanan } \\
\text { BKP, } \\
\text { Langkah } \\
\text { BKP }\end{array}$ & $\begin{array}{l}\text { Konselo } \\
\text { r } \\
\text { melaksa } \\
\text { nakan } \\
\text { kegiatan } \\
\text { layanan } \\
\text { Siswa } \\
\text { Disiplin } \\
\text { Langkah } \\
\text { Sesuai } \\
\text { dengan } \\
\text { skenario } \\
\text { dan } \\
\text { langkah- } \\
\text { langkah } \\
\text { BKP } \\
\text { Siswa } \\
\text { mengiku } \\
\text { ti } \\
\text { layanan } \\
\text { pembela } \\
\text { jaran } \\
\text { sesuai } \\
\text { dengan } \\
\text { peran } \\
\text { yang }\end{array}$ & $\begin{array}{l}\text { Penel } \\
\text { iti } \\
\text { dan } \\
\text { Obse } \\
\text { rver }\end{array}$ \\
\hline
\end{tabular}

\begin{tabular}{|c|c|c|c|}
\hline & & $\begin{array}{l}\text { dituntut } \\
\text { dalam } \\
\text { BKP }\end{array}$ & \\
\hline $\begin{array}{l}\text { Observ } \\
\text { asi }\end{array}$ & $\begin{array}{l}\text { Memantau/ } \\
\text { mengamati } \\
\text { pelaksanaan } \\
\text { kegiatan } \\
\text { layanan BKP } \\
\text { dan } \\
\text { Observasi } \\
\text { tentang } \\
\text { disiplin }\end{array}$ & $\begin{array}{l}\text { Data } \\
\text { tentang } \\
\text { kesesuia } \\
n \\
\text { pelaksan } \\
\text { aan } \\
\text { tindakan } \\
\text { dengan } \\
\text { rencana } \\
\text { tindakan } \\
\text { Data } \\
\text { tentang } \\
\text { sejauhm } \\
\text { ana } \\
\text { pelaksan } \\
\text { aan } \\
\text { tindakan } \\
\text { menunju } \\
\text { kkan } \\
\text { ketercap } \\
\text { aian } \\
\text { tujuan } \\
\text { tindakan } \\
\text { Data } \\
\text { tentang } \\
\text { faktor } \\
\text { penduku } \\
\text { ng dan } \\
\text { pengha } \\
\text { mbat } \\
\text { dari } \\
\text { tindakan }\end{array}$ & $\begin{array}{l}\text { Penel } \\
\text { iti } \\
\text { dan } \\
\text { Obse } \\
\text { rver }\end{array}$ \\
\hline $\begin{array}{l}\text { Evalua } \\
\text { si }\end{array}$ & $\begin{array}{l}\text { Menganalisi } \\
\mathrm{s} \text { data dan } \\
\text { menyimpulk } \\
\text { an } \\
\text { keberhasilan }\end{array}$ & $\begin{array}{l}\text { Partisipa } \\
\text { si siswa } \\
\text { secara } \\
\text { aktif } \\
\text { selama } \\
\text { mengiku } \\
\text { ti } \\
\text { kegiatan } \\
\text { layanan } \\
\text { dengan } \\
\text { kemamp } \\
\text { uan } \\
\text { menulis } \\
\text { teks } \\
\text { prosedur }\end{array}$ & $\begin{array}{l}\text { Penel } \\
\text { iti } \\
\text { dan } \\
\text { Obse } \\
\text { rvasi }\end{array}$ \\
\hline $\begin{array}{l}\text { Reflek } \\
\text { si }\end{array}$ & $\begin{array}{l}\text { Mengkaji } \\
\text { berbagai hal } \\
\text { yang timbul } \\
\text { dalam } \\
\text { menulis teks }\end{array}$ & $\begin{array}{l}\text { Keungg } \\
\text { ulan dan } \\
\text { kelemah } \\
\text { an } \\
\text { tindakan }\end{array}$ & $\begin{array}{l}\text { Penel } \\
\text { iti }\end{array}$ \\
\hline
\end{tabular}




\begin{tabular}{|l|l|l|}
\hline prosedur & Tantang \\
an dan \\
peluang \\
tindakan \\
Informa \\
si \\
sebagai \\
bahan \\
masukan \\
yang \\
berguna \\
bagi \\
pengem \\
bangan \\
rencana \\
tindakan \\
ke II \\
(dua)
\end{tabular}

Dalam penelitian ini yang menjadi subjek penelitian adalah siswa kelas XI Mia I di MAN I Medan yang berjumlah 35 orang. Sedangkan objek dalam penelitian ini adalah meningkatkan kemampuan menulis teks prosedur siswa kelas XI Mia I di MAN I Medan dengan model problem based learning tahun Pembelajaran 2019/2020.

\section{Hasil Penelitian}

\section{Siklus I}

Dari data yang diperoleh pada saat tes kemampuan awal diperoleh data bahwa ada sekitar $81,82 \%$ siswa memperoleh nilai di bawah 65 dan rata-rata kelas yang diperoleh adalah 42,41 sehingga dikategorikan dalam kemampuan sangat rendah. Berdasarkan hasil tes kemampuan awal siswa tersebut maka perlu diadakan

\begin{tabular}{|c|c|c|c|c|c|}
\hline \multirow[t]{2}{*}{ Pertemuan } & \multicolumn{5}{|c|}{$\begin{array}{l}\text { Prosentese Rerata } \quad \text { Frekuensi } \\
\text { Aktivitas Siswa Untuk Kategori }(\%)\end{array}$} \\
\hline & 1 & 2 & 3 & 4 & 5 \\
\hline I & 14.00 & 17.33 & 22.50 & 17.33 & 7.50 \\
\hline II & 19.50 & 16.50 & 24.83 & 19.50 & 5.83 \\
\hline III & 22.33 & 14.00 & 25.50 & 22.33 & 5.83 \\
\hline $\begin{array}{l}\text { Rerata } \\
\text { Prosentase }\end{array}$ & 18.61 & 15.94 & 24.28 & 19.72 & 6.39 \\
\hline
\end{tabular}
permasalahan yang dialami siswa agar hasil belajar siswa dapat meningkat.

\section{Observasi Aktivitas Siswa Siklus I}

Rerata prosentase waktu yang digunakan siswa untuk melakukan masing - masing kategori menulis teks prosedur selama tiga kali pertemuan adalah $18,61 \%$ ; $15,94 \% ; 24,28 \% ; 19,72 \%$ dan $6,39 \%$.

\section{Siklus II}

Hasil dari observasi aktivitas belajar siswa ditunjukkan dalam tabel berikut ini :

\section{Observasi Aktivitas Siswa Siklus II}

\begin{tabular}{|l|l|l|l|l|l|}
\hline \multirow{2}{*}{$\begin{array}{l}\text { Perte } \\
\text { muan }\end{array}$} & \multicolumn{4}{|l}{ Prosentese Rerata Frekuensi } & \multicolumn{2}{l|}{ Aktivitas } \\
\cline { 2 - 6 } & 1 & 2 & 3 & 4 & 5 \\
\hline I & 24.00 & 15.00 & 27.00 & 24.00 & 5.00 \\
\hline II & 24.00 & 15.00 & 27.00 & 24.00 & 5.00 \\
\hline III & 27.00 & 17.00 & 27.00 & 27.00 & 3.00 \\
\hline $\begin{array}{l}\text { Rerata } \\
\text { Prosen } \\
\text { tase }\end{array}$ & 25.00 & 15.66 & 27.00 & 25.00 & 4.33 \\
\hline
\end{tabular}

Rerata prosentase waktu yang digunakan siswa untuk melakukan masing - masing kategori aktivitas menulis teks prosedur selama tiga kali pertemuan adalah $25 \%$; $15,66 \% ; 27 \%$; $25 \%$ dan 4,33\%. Maka dapat diperoleh data bahwa ada peningkatan aktivitas menulis teks prosedur siswa dari siklus pertama ke siklus ke dua hal ini terjadi cukup signifikan untuk setiap aktivitas hanya saja ada dua aktivitas menulis teks prosedur yang turut mengalami penurunan dari siklus satu ke siklus dua namun tetap bisa memenuhi syarat keidealan yang telah di tetapkan. Untuk lebih jelas besarnya kenaikan atau perubahan aktivitas menulis teks prosedur siswa akan direpresentasikan melalui grafik di bawah ini.

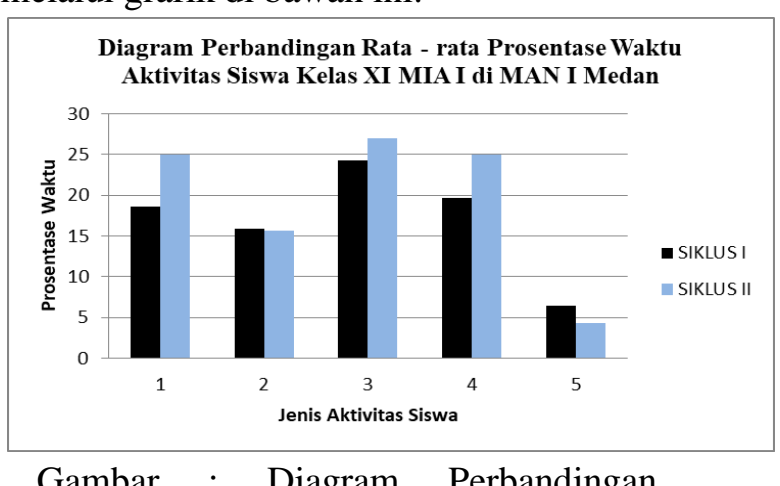

Gambar : Diagram Perbandingan Prosentase Waktu Aktivitas menulis teks prosedur Siswa

Selain itu diperoleh juga peningkatan hasil belajar siswa secara klasikal yaitu $61,36 \%$ pada siklus I menjadi $88,63 \%$ pada siklus

II. Berarti siklus II ini sudah mencapai ketuntasan belajar klasikal 


\section{KESIMPULAN}

Berdasarkan hasil penelitian kesimpulan yang di dapat dalam penelitian ini adalah Rerata prosentase waktu yang digunakan siswa untuk melakukan masing - masing kategori menulis teks prosedur selama tiga kali pertemuan adalah $18,61 \% \quad ; 15,94 \%$; $24,28 \% ; 19,72 \%$ dan $6,39 \%$. Rerata prosentase waktu yang digunakan siswa untuk melakukan masing - masing kategori aktivitas menulis teks prosedur selama tiga kali pertemuan adalah $25 \%$; $15,66 \% ; 27 \%$; $25 \%$ dan 4,33\%. Maka dapat diperoleh data bahwa ada peningkatan aktivitas menulis teks prosedur siswa dari siklus pertama ke siklus ke dua hal ini terjadi cukup signifikan untuk setiap aktivitas hanya saja ada dua aktivitas menulis teks prosedur yang turut mengalami penurunan dari siklus satu ke siklus dua namun tetap bisa memenuhi syarat keidealan yang telah di tetapkan.

\section{DAFTAR PUSTAKA}

Arikunto, Suharsimi. 2013. Prosedur Penelitian. Jakarta : Rineka Cipta.

Djamarah, Zain. 2006. Strategi Belajar Mengajar. Jakarta : Rineka Cipta.

Hosnan. 2014. Pendekatan Saintifik dan Kontekstual dalam Pembelajaran abad ke.21. Jakarta : Ghalia Indonesia.

Priyatni , Endah Try. 2014. Desain Pembelajaran Bahasa Indonesia dalam kurikulum 2013. Jakarta: Bumi Aksara.

Sugiyono.2013. Pengantar Statistik Pendidikan. Jakarta: PT Raja Grafindo Persada. 